\title{
Correspondance
}

\section{Ovarian cancer screening}

$\mathrm{U}$ sha Menon's review of ovarian cancer screening ${ }^{1}$ appears to misquote the result of the randomized controlled trial of multimodal screening (with the tumour marker CA125 and ultrasonography) by Jacobs and associates. ${ }^{2}$

In that study the number of deaths from ovarian cancer was 18 among the 10977 patients in the control group and 9 among the 10958 patients in the screened group (relative risk of death in the unscreened group 2.0, 95\% confidence interval 0.78-5.13); Menon's article seems to state the reverse. Although the difference in number of deaths was not statistically significant, these results represent a possible halving of the death rate by screening, rather than a possible doubling.

\section{Erica L. Eason}

Associate Professor

Obstetrics and Gynaecology

University of Ottawa

Ottawa, Ont.

\section{References}

1. Menon U. Ovarian cancer screening. CMAf 2004;171(4):323-4.

2. Jacobs IJ, Skates SJ, MacDonald N, Menon U, Rosenthal AN, Davies AP, et al. Screening for ovarian cancer: a pilot randomised controlled trial. Lancet 1999;353(9160):1207-10.

DOI:10.1503/cmaj.1041644

$\mathrm{U}$ sha Menon, ${ }^{1}$ in an analysis of ovarian cancer screening, points out that the best evidence for screening comes from a study that found significant longer median survival with screening but no significant difference in the number of deaths from ovarian or fallopian tube cancer. ${ }^{2}$ This sounds like a classic example of lead-time bias, in which earlier diagnosis of a disease has no impact on the patient's outcome. In other words, the patient may die of the disease at the same time as she would have if the diagnosis had been made 30 months later. Median survival may appear better, but in fact all we've done is to give the patient a longer cancer experience, without better quality or quantity of life.
If this is the best evidence we have for ovarian cancer screening, then I certainly agree that "Screening is not currently recommended for the general population."

\section{David M. Allen}

Sudbury, Ont.

\section{References}

1. Menon U. Ovarian cancer screening. CMAf 2004:171(4):323-4.

2. Jacobs IJ, Skates SJ, MacDonald N, Menon U, Rosenthal AN, Davies AP, et al. Screening for ovarian cancer: a pilot randomised controlled trial. Lancet 1999;353(9160):1207-10.

DOI:10.1503/cmaj.1041601

\section{Treating $C$. difficile}

$\mathrm{I}_{\mathrm{a}}^{\mathrm{n}}$ n their review of Clostridium difficileassociated diarrhea, ${ }^{1}$ Susan Poutanen and Andrew Simor note that concurrent administration of probiotic agents (e.g., Saccharomyces boulardii and Lactobacillus $G G$ ) and antibiotics to prevent recurrence of the problem has yielded mixed results.

There is substantial overlap among antibiotic use, $C$. difficile colonization and subsequent $C$. difficile-induced diarrhea. In fact, $26 \%$ to $50 \%$ of antibioticassociated diarrhea can be attributed to $C$. difficile. ${ }^{2}$ A meta-analysis ${ }^{3}$ of $S$. boulardii and Lactobacillus GG co-administered with antibiotics (including the antibiotics regarded as the most common inducers of diarrhea [ampicillin, cephalosporins, clindamycin $]^{2,4}$ ) for treatment of antibiotic-associated diarrhea in a diverse population (881 patients of all ages, including inpatients, outpatients and people from developing countries) provided strong evidence to suggest that probiotic agents prevent antibiotic-associated diarrhea (relative risk $0.40,95 \%$ confidence interval [CI] $0.28-0.57)$. A larger meta-analysis (1380 patients) of 7 probiotic species administered with a host of antibiotics provided further evidence of the effectiveness of probiotics for the prevention of antibiotic-associated diarrhea (odds ratio 0.37 , 95\% CI 0.26-0.53). ${ }^{5}$
However, these meta-analyses are limited, in that they provided little information about the species and doses that would yield the most beneficial results and did not identify the patient population(s) that would benefit most. In addition, neither author group performed a meta-analysis for adverse events, nor did they comment on why such an analysis was not done. We might assume that only minor adverse events were reported in the randomized controlled trials reviewed; however, meta-analyses of such trials often overlook important details. ${ }^{6}$ Although no adverse events were reported in these meta-analyses, infections resulting from probiotic use (e.g., bacteremia, endocarditis, septicemia, pneumonia and deep abdominal abscesses) have been reported in neonates and severely debilitated and immunocompromised individuals. ${ }^{7}$ It is unclear, however, whether exogenous or endogenous Lactobacilli were the cause of the few cases of Lactobacillus bacteremia that have been reported. ${ }^{8}$

The public health burden of this problem is substantial and the preliminary evidence promising; as such, concurrent use of probiotics with antibiotics in the hospital setting is worth further consideration. However, a research agenda is needed to determine which probiotic species and dosages might provide effective prophylaxis and which hospital population(s) would benefit most.

\section{Bradley C. Johnston}

Graduate Student

Sunita Vohra

Director, Complementary and

Alternative Research and Education

(CARE) Program

Department of Pediatrics

University of Alberta

Edmonton, Alta.

\section{References}

1. Poutanen SM, Simor AE. Clostridium difficile-associated diarrhea in adults. CMA7 2004;171 (1):51-8.

2. McFarland LV. Epidemiology, risk factors and treatments for antibiotic-associated diarrhea. $\mathrm{Dig}$ Dis 1998;16:292-307. 
3. Cremonini F, DiCaro S, Nista EC, Bartolozzi F, Capelli G, Gasbarrini G, et al. Meta-analysis: the effect of probiotic administration on antibiotic associated diarrhoea. Aliment Pharmacol Ther 2002;16:1461-7.

4. Louie TJ, Meddings J. Clostridium difficile infection in hospitals: risk factors and responses [editorial]. CMA7 2004;171(1):45-6.

5. D'Souza A, Rajkumar C, Cooke J, Bulpitt CJ Probiotics in prevention of antibiotic associated diarrhoea: meta-analysis. BM7 2002;324:1361.

6. Hopayian $\mathrm{K}$. The need for caution in interpreting high quality systematic reviews. $B M 72001$; 323:681-4

7. Salminen S, von Wright A, Morelli L, Marteau P, Brassart D, de Vos WM, et al. Demonstration of safety of probiotics - a review. Int 7 Food Mi crobiol 1998;44:93-106.

8. Salminen MK, Rautelin H, Tynkkynen S. Poussa T, Saxelin M, Valtonen V, et al. Lactobacillus bacteremia, clinical significance, and patient outcome, with special focus on probiotic $L$. rhamnosus GG. Clin Infect Dis 2004;38(1):62-9.

Competing interests: Funding: Bradley Johnston is funded by the University of Alberta Evidence-based Practice Centre and The Hospital for Sick Children Foundation.

DOI:10.1503/cmaj.1041646

$\mathrm{I}^{\mathrm{n}}$ their comprehensive review of Clostridium difficile-associated diarrhea (CDAD), Susan Poutanen and Andrew Simor ${ }^{1}$ refer to the use of anionbinding resins (colestipol or cholestyramine). It is important to highlight the timing of administration of these agents in relation to other oral therapeutic agents (metronidazole or vancomycin). In addition to binding the toxin and spores of $C$. difficile, the binding agents may also bind orally administered therapeutic agents to various degrees, thereby negating their effect. Ideally, resin binders should be given either an hour before or 4 to 6 hours after administration of the oral antibiotics $^{2}$ to avoid this problem. However, in clinical practice, especially in hospitals, I have found that the binders and other agents are often given simultaneously; many of the patients have recurrent disease, are described as being resistant to metronidazole (an otherwise rare situation) and are subsequently given oral vancomycin, which is more costly. I believe that this is a common cause of iatrogenic resistance to oral metronidazole.

There are no studies of this phenomenon (i.e., no evidence in this era of evidenced-based and "evidencemade" ${ }^{3}$ medicine), but on the basis of a theoretical understanding of the patho- physiology of CDAD, I often administer 10 to 14 days of oral metronidazole followed by 5 to 7 days of oral cholestyramine (to bind the remaining spores in the gut) and have observed a very low rate of recurrence. It is time to prospectively evaluate this simple strategy of sequential therapy in the management of CDAD in a randomized trial.

\section{Malvinder S. Parmar}

Associate Professor, Medicine

Northern Ontario School of Medicine

Laurentian and Lakehead Universities

Sudbury and Thunder Bay, Ont.

\section{References}

1. Poutanen SM, Simor AE. Clostridium difficile-associated diarrhea in adults. CMAF 2004; 171(1):51-8.

2. Questran [product monograph]. In: Compendium of pharmaceuticals and specialties. Ottawa: Canadian Pharmacists Association; 2003. p. 1411-2.

3. Parmar MS. Evidence made medicine. 7 Postgrad Med 2004;50(2):118-9.

Competing interests: None declared.

DOI:10.1503/cmaj.1041195

[The authors respond to Dr. Parmar:]

W e agree with Malvinder Parmar that the role of anion-binding resins in the treatment of CDAD needs to be studied further. Anion-binding resins, such as cholestyramine and colestipol, have been shown to bind $C$. difficile toxins ${ }^{1}$ and have consequently been proposed as potentially useful in the treatment of CDAD, as we mentioned in our review. ${ }^{2}$ Parmar also suggests that anion-binding resins may also bind $C$. difficile spores, but to the best of our knowledge, this phenomenon has not been described in published reports. Small numbers of mostly anecdotal reports of success and failure with the use of anion-binding resins in the treatment of CDAD have been published (summarized by Ariano and associates ${ }^{3}$ ), but no large randomized controlled trials have been completed to definitively determine the role of resins. Anion-binding resins have been shown to bind vancomycin ${ }^{1,4}$ and theoretically may bind other antibiotics such as metronidazole, although we are not aware of any pub- lished data specifically describing this. Given the possibility of antibiotic binding by resins, some authors have suggested not using anion-binding resins in the treatment of CDAD, ${ }^{5}$ whereas others recommend using them only if administered at different times from metronidazole or vancomycin. ${ }^{6}$ As Parmar suggests, more study is needed to address the optimal indication and timing of anion-binding resins in the treatment of CDAD.

\section{Susan M. Poutanen}

Andrew E. Simor

Department of Laboratory Medicine and Pathobiology

University of Toronto

Toronto, Ont.

\section{References}

1. Taylor NS, Bartlett JG. Binding of Clostridium difficile cytotoxin and vancomycin by anion-exchange resins. F Infect Dis 1980;141:92-7.

2. Poutanen SM, Simor AE. Clostridium difficile-associated diarrhea in adults. CMA7 2004 171(1):51-8.

3. Ariano RE, Zhanel GG, Harding GK. The role of anion-exchange resins in the treatment of antibiotic-associated pseudomembranous colitis. CMA7 1990;142(10):1049-51.

4. Pantosti A, Luzzi I, Cardines R, Gianfrilli P Comparison of the in vitro activities of teicoplanin and vancomycin against Clostridium difficile and their interactions with cholestyramine. Antimicrob Agents Chemother 1985;28:847-8.

5. Wilcox MH. Treatment of Clostridium difficile infection. 7 Antimicrob Chemother 1998;41:41-6.

6. Malnick SD, Zimhony O. Treatment of Clostridium difficile-associated diarrhea. Ann Pharmacother 2002;36:1767-75.

Competing interests: None declared.

DOI:10.1503/cmaj.1041461

\section{Cobalamin deficiency in elderly patients}

$\mathrm{H}$ mmanuel Andrès and colleagues, ${ }^{1}$ diagnosis and treatment of vitamin $B_{12}$ (cobalamin) deficiency, fail to consider 2 elements relevant to the Canadian experience.

First, because Canada's flour supply is fortified with folic acid, ${ }^{2}$ plasma homocysteine level (determined primarily by folate status) is much less effective in the diagnostic work-up of suspected cobalamin deficiency. ${ }^{3}$ In a large population-based study, we established the 